\title{
PREDICTION OF FORMATION OF DYNAMICALLY STABLE EBB TIDAL DELTA AND MEASURES FOR PREVENTING OFFSHORE SAND LOSS
}

\author{
Takaaki Uda' ${ }^{1}$, Masumi Serizawa ${ }^{2}$, Toshiro San-nami² and Toshinori Ishikawa'
}

\begin{abstract}
We developed a model for predicting the evolution of an ebb tidal delta based on the BG model, which was proposed by the present authors using the Bagnold concept of the equilibrium slope. Bathymetric changes around the inlet of Imagire-guchi between 1978 and 2005 were quantitatively analyzed to investigate the evolution of the ebb tidal delta and sand deposition offshore of the inlet. The model was applied to this inlet. The predicted bathymetric changes were in good agreement with the measured changes. Some measures for preventing the offshore sand loss were also considered by applying the model. The most effective measure was predicted to be cross-shore sand bypassing.
\end{abstract}

Keywords: ebb tidal delta; predictive model; beach changes; $B G$ model; cross-shore sand bypassing

\section{INTRODUCTION}

At a tidal inlet on a coast with predominant longshore sand transport, part of the transported sand is trapped owing to the ebb tidal currents flowing outward approximately perpendicular to the direction of longshore currents. This blockage of longshore sand transport causes the formation of an ebb tidal delta offshore of the inlet, resulting in a significant amount of sand loss from the shoreline zone, which in turn causes downcoast erosion. Imagire-guchi jetty is located at the tidal inlet connecting Lake Hamana with the Pacific Ocean (Fig. 1). Past studies have revealed that this jetty blocks westward longshore sand transport, the predominant transport on the Enshu-nada coast, causing downcoast erosion; this loss of sand into the offshore zone cannot be neglected in terms of the comprehensive management of sand on coasts. Tung et al. (2007) predicted the evolution of ebb tidal deltas using the Delft 3-D model. In their model, the full equations of waves and nearshore and tidal currents were solved to predict threedimensional bathymetric changes. For practical applications, however, the development of a model by which bathymetric changes can be easily predicted and used for investigating measures against beach erosion is also desirable. Serizawa et al. (2008) developed a model for predicting the bathymetric changes around a tidal inlet under the action of both waves and currents by modeling the effect of ebb tidal currents by a jet flow emerging from the inlet. The validation of their model, however, was inadequate regarding the evolution process of a delta through the comparison with field data, although the formation of a dynamically stable ebb tidal delta was successfully predicted using the model.
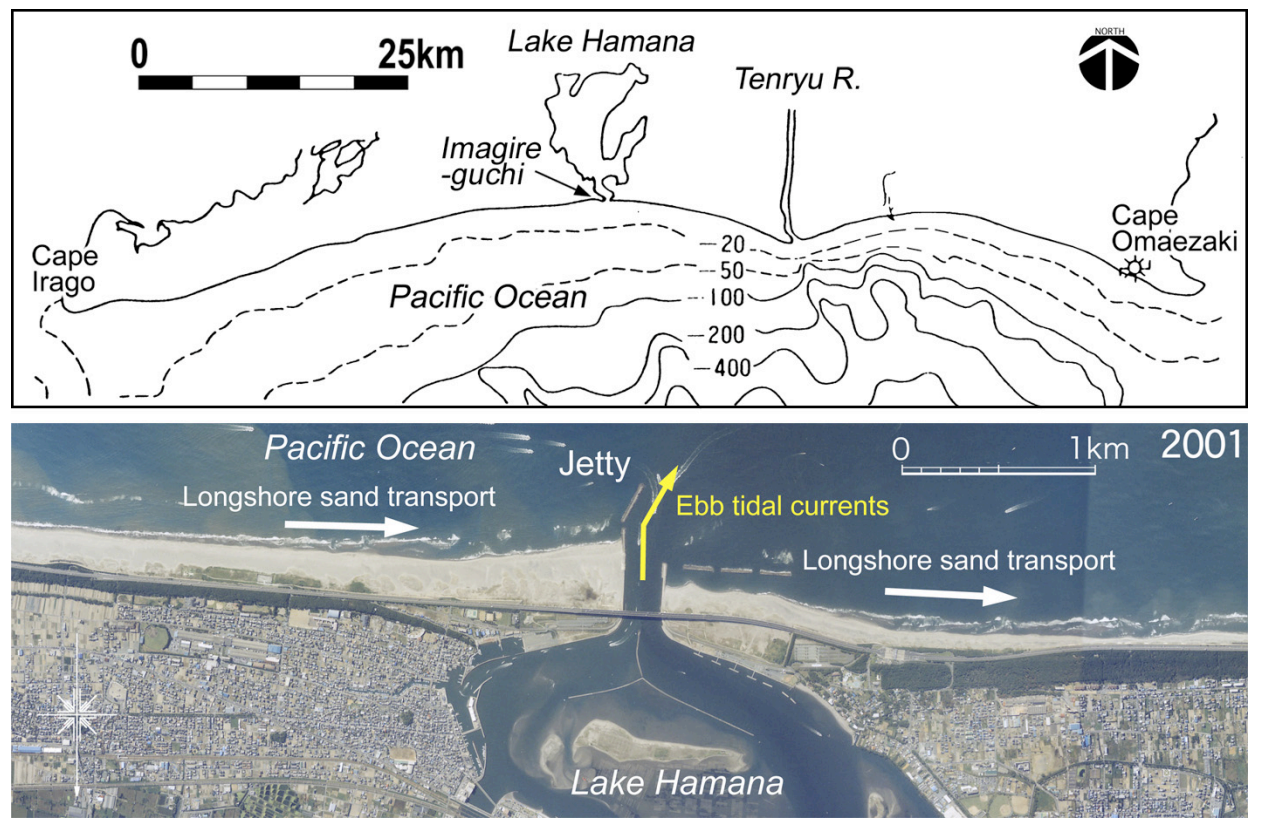

Figure 1. Location of Imagire-guchi jetty on Enshu-nada coast.

\footnotetext{
${ }^{1}$ Public Works Research Center, 1-6-4 Taito, Taito, Tokyo 110-0016, Japan

${ }^{2}$ Coastal Engineering Laboratory Co., Ltd., 301, 1-22 Wakaba, Shinjuku, Tokyo 160-0011, Japan
} 
Therefore, it was difficult to investigate measures to prevent sand loss into the offshore zone using their model. In this study, bathymetric changes between 1978 and 2005 around Imagire-guchi jetty, for which the characteristics of tidal currents have been measured by Syamsidik et al. (2008), were investigated and the evolution process of an ebb tidal delta and bathymetric changes were quantitatively predicted. Moreover, some measures for preventing sand loss into the offshore zone were numerically investigated and compared.

\section{MODEL}

The fundamental equations of the model developed by Serizawa et al. (2008) were improved to take into account the differences in the intensity of cross-shore and longshore sand transport. Assume that the total sand transport $\vec{q}$ is a linear sum of the sand transport due to waves $\overrightarrow{q_{w}}$ and that due to ebb tidal currents $\overrightarrow{q_{R}}$, as shown by Eq. (1).

$$
\vec{q}=\overrightarrow{q_{w}}+\overrightarrow{q_{R}}
$$

For the equation of sediment transport due to waves, the equation given by Serizawa et al. (2006) was employed, which was derived by applying the concept of the equilibrium slope introduced by Inman and Bagnold (1963) and the energetic approach by Bagnold (1963), similar to the previous study (Serizawa et al., 2008). Consider Cartesian coordinates $(x, y)$, where the $x$-axis and $y$-axis are taken to be the cross-shore distance (positive for shoreward) and longshore distance parallel to the shoreline, respectively. The elevation at a point $Z(x, y, t)$ is a variable to be solved. Assume that waves are obliquely incident to a coast with a uniform slope of $\tan \beta$. Then, the net sand transport flux due to waves $\overrightarrow{q_{w}}=\left(q_{w x}, q_{w y}\right)$ is written as

$$
\begin{aligned}
& q_{w x}=\frac{G_{w x}}{\tan \beta_{\mathrm{c}}}\left[\tan \beta_{\mathrm{c}} \cos \theta_{\mathrm{w}}-\frac{\partial Z}{\partial x}\right] \\
& q_{w y}=\frac{G_{w y}}{\tan \beta_{\mathrm{c}}}\left[\tan \beta_{\mathrm{c}} \sin \theta_{\mathrm{w}}-\frac{\partial Z}{\partial y}\right]
\end{aligned}
$$

Here, $G_{w x}$ and $G_{w y}$ are given by Eqs. (3)-(7).

$$
\begin{gathered}
G_{w x}=K_{x} G_{w}, G_{w y}=K_{y} G_{w} \\
G_{w}=C_{0} \Phi=C_{0} \varepsilon(Z)\left(E C_{g}\right)_{b} \cos ^{2} \alpha_{b} \tan \beta_{c} \\
C_{0}=\frac{1}{\left(\rho_{s}-\rho\right) g(1-p)} \\
\varepsilon(Z)= \begin{cases}\int_{-h_{c}}^{h_{R}} \varepsilon(Z) d Z=1 \\
=\frac{1}{h_{c}+h_{R}} & \left(-h_{c} \leq Z \leq h_{R}\right) \\
= & \left(Z<-h_{c}, h_{R}<Z\right) .\end{cases}
\end{gathered}
$$

Here, $q_{x}$ is the cross-shore component of sediment transport flux (positive for shoreward), $q_{y}$ is the longshore component of sediment transport flux, $\theta_{w}$ is the angle between the wave direction and the $x$ axis, $\nabla Z=(\partial Z / \partial x, \partial Z / \partial y)$ is the gradient of $Z$, the direction and magnitude of which give the shoreward normal to the contour line and $\tan \beta$, respectively. $\Phi$ is the wave energy dissipation rate per unit time and unit seabed area, $\left(E C_{g}\right)_{b}$ is the wave energy flux at the breaking point, $\alpha_{b}$ is the breaker angle, $K_{x}$ and $K_{y}$ are the coefficients of cross-shore and longshore sand transport, $C_{0}$ is the coefficient through which the sand transport rate, expressed in terms of the immersed weight, is related to the volumetric sand transport rate, $\rho_{s}$ and $\rho$ are the sand and water densities, and $g$ is the acceleration due to gravity, respectively. $P$ is the porosity of the sand, $h_{c}$ is the depth of closure, and $h_{R}$ is the berm height corresponding to the wave run-up height. $\varepsilon(Z)$ is the depth distribution of the intensity of longshore sand transport and is defined so that the integral over the depth between $Z=-h_{c}$ and $h_{R}$ is equal to 1 , and in this study, the uniform distribution given by Eq. (7) is assumed. $\tan \beta_{c}$ is the equilibrium slope for 
which zero net cross-shore transport occurs when waves are incident from the direction normal to the slope. This represents the balance between the upslope flow asymmetry and the downslope component of gravity (Inman and Bagnold, 1963; Bailard and Inman, 1981).

Regarding Eqs. (2) and (3), Serizawa et al. (2008) used the sediment transport equation proposed by Serizawa et al. (2006) by setting the index of wave direction reversal $\lambda$ to be 0 . This implicitly assumes that the coefficients of cross-shore and longshore sand transport are equivalent. In this study, to take the difference in the intensities of cross-shore and longshore sand transport into account, the coefficients of cross-shore and longshore sand transport, $K_{x}$ and $K_{y}$, were determined independently.

In this study, the $y$-axis was taken parallel to the initial shoreline and the ratio of the coefficients of cross-shore and longshore sand transport, $K_{x} / K_{y}$, was assumed to be 0.2 . When assuming $K_{x} / K_{y}=1.0$ as in Serizawa et al. (2008), the ebb tidal delta markedly protruded offshore with a small aspect ratio. When the intensity of longshore sand transport was increased relative to that of cross-shore sand transport, the protrusion of the ebb tidal delta was reduced, resulting in the formation of contours with a small curvature in the longshore direction.

Regarding the sand transport $\overrightarrow{q_{R}}=\left(q_{R x}, q_{R y}\right)$ due to ebb tidal currents, Eq. (8), the same equation as that used by Serizawa et al. (2008), was employed, which was derived by Bailard and Inman (1981) from the bed load transport formula of Bagnold (1963) by a linear approximation of the seabed slope.

$$
\begin{aligned}
& q_{R x}=\frac{G_{R}}{\tan \phi}\left[\tan \phi \cos \theta_{R}-\frac{\partial Z}{\partial x}\right] \\
& q_{R y}=\frac{G_{R}}{\tan \phi}\left[\tan \phi \sin \theta_{R}-\frac{\partial Z}{\partial y}\right]
\end{aligned}
$$

Here, the subscript $R$ denotes the ebb tidal currents, $\theta_{R}$ is the angle between the direction of the ebb tidal currents and the $x$-axis and $\tan \phi$ is the angle of repose of the sand. In the original equation by Bailard and Inman (1981), the coefficient $G_{R}$ in Eq. (8) is expressed in terms of the instantaneous velocity, the angle of repose of the sand and a friction factor, but in this study, sand transport due to currents is assumed to satisfy an equation with the same form as Eq. (2), and all these effects are included in the coefficient $G_{R}$ in Eq. (8). The first and second terms in the parentheses in Eq. (8) corresponds to the action of currents and downslope action due to gravity, respectively. $G_{R}$ is given by

$$
G_{R}=\left\{\begin{array}{l}
=C_{0} K_{R} F_{w} K_{V}^{3} \quad\left(-h_{c 2} \leq Z \leq h_{R 2}\right) \\
=0 \quad\left(Z<-h_{c 2}, h_{R 2}<Z\right) .
\end{array}\right.
$$

Here, $K_{R}$ is the coefficient of sand transport due to ebb tidal currents. $h_{c 2}$ and $h_{R 2}$ are the lower and upper depths at which bathymetric changes are induced by tidal currents, respectively. The explanation of the parameters is the same as that in Serizawa et al. (2008). In this study, the action of the ebb tidal currents is evaluated macroscopically, and $G_{R}$ is expressed in terms of the intensity of the tidal currents relative to the wave intensity $\left(E C_{g}\right)_{b 0}$ and is assumed to be zero outside the zone between the upper and lower depths at which bathymetric changes are induced by the ebb tidal currents. $G_{R}$ in Eq. (9) represents the work done by the ebb tidal currents in transporting the sand and is proportional to the energy dissipation rate of the ebb tidal currents (Bagnold, 1963; Bailard and Inman, 1981). Furthermore, $G_{R}$ is assumed to be proportional to the third power of the velocity ratio, so that the energy dissipation rate is proportional to the third power of the velocity (Bagnold, 1963; Bailard and Inman, 1981). The coefficients in Eq. (9) are written as

$$
\begin{gathered}
F_{w}=\frac{\left(E C_{g}\right)_{b 0}}{h_{c}+h_{R}} \\
K_{V}=\frac{V}{V_{0}}=K_{V 1}\left(\frac{h_{0}}{h}\right) \\
K_{V 1}=\left(\frac{V_{1}}{V_{0}}\right)
\end{gathered}
$$


Here, $K_{V}$ is the ratio of tidal current velocity to $V_{0}, V / V_{0}$, where $V$ is the velocity of ebb tidal currents and $V_{0}$ is a reference velocity at the inlet. $F_{w}$ is a characteristic value of the intensity of wave action, it is given by the wave energy flux at the breaking point used as the reference point and is equal to $\left(E C_{g}\right)_{b 0}$ divided by the sum of $h_{c}$ and $h_{R}$, as in Eq. (10). $V_{1}$ is the flow velocity of the ebb tidal currents on the plane bottom. $K_{V 1}$ is the ratio of velocity to the flow velocity at the inlet on the plane bottom.

The distribution of the ebb tidal currents through a tidal inlet is very similar to that of a jet flowing into still water, which in turn is similar to the distribution of the wave diffraction coefficient of waves diffracted through the opening of impermeable breakwaters (Serizawa et al., 2008). Taking this fact into account, the angular spreading method for irregular waves proposed by Sakai et al. (2006) was applied to calculate the ratio of the velocities $K_{V 1}$ under a constant depth condition.

\section{CALCULATION CONDITIONS}

Around Imagire-guchi jetty, bathymetric surveys with high accuracy have been carried out since 1978, and therefore the bathymetric changes since 1978 were used to validate the numerical model. Given the parallel contours before the construction of the jetty as the initial condition, the bathymetry in 1978 was first predicted, and then the bathymetric changes between 1978 and 2005 were predicted, enabling the comparison of the predicted development of the ebb tidal delta with measurements. During this period, the ebb tidal currents were intensified because of scouring in the inlet channel associated with the extension of the jetty, and the coefficient of intensity of ebb tidal currents was linearly increased over time from $K_{v}=0.1$ in 1978 to 0.3 in 2005 .

The west jetty at Imagire-guchi is longer than the east jetty, causing the development of oblique ebb tidal currents. The effect of oblique currents between jetties of different length was modeled by a jet obliquely emerging from the inlet with an angle of $30^{\circ}$ relative to the normal to the shoreline, so that the assumed direction of the jet currents coincides with that of the ebb tidal currents measured at Imagire-guchi inlet by Syamsidik et al. (2008). In the calculation, the change in wave energy intensity associated with the wave refraction in Eq. (4) was neglected for simplicity, and we assumed that $\cos \alpha_{b}$ $=1$. In addition, the lower depth at which bathymetric changes are induced by tidal currents $h_{c 2}$ was

\begin{tabular}{|c|c|}
\hline \multicolumn{2}{|c|}{ Table 1. Calculation conditions. } \\
\hline Initial topography & uniform slope of $1 / 70$ \\
\hline Equilibrium slope & $\tan \beta_{c}=1 / 70$ \\
\hline Slope of angle of repose & $\tan \phi=1 / 2$ \\
\hline Wave conditions & $\begin{array}{l}H_{b}=3 \mathrm{~m}, \text { breaker angle } \theta_{w}=10^{\circ}, H_{b 0}=1 \mathrm{~m} \text { in } \\
\text { calculating }\left(E C_{g}\right)_{b 0}\end{array}$ \\
\hline $\begin{array}{l}\text { Depth distribution of intensity of longshore } \\
\text { sand transport }\end{array}$ & Uniform \\
\hline $\begin{array}{l}\text { Coefficients of longshore and cross-shore } \\
\text { sand transport }\end{array}$ & $K_{y}=0.0105$ and $K_{x}=0.2 K_{y}$ \\
\hline Berm height & $h_{R}=3 \mathrm{~m}$ \\
\hline Depth of closure & $h_{c}=8 \mathrm{~m}$ \\
\hline $\begin{array}{l}\text { Coefficient of sediment transport due to ebb } \\
\text { tidal currents }\end{array}$ & $\begin{array}{l}K_{R}=0.1-0.3 \text { for reproduction and } K_{R}=0.3 \text { for } \\
\text { prediction }\end{array}$ \\
\hline $\begin{array}{l}\text { Upper depth of bathymetric changes induced } \\
\text { by tidal currents }\end{array}$ & $h_{R 2}=0 \mathrm{~m}$ \\
\hline $\begin{array}{l}\text { Lower depth of bathymetric changes induced } \\
\text { by tidal currents }\end{array}$ & $h_{c 2}=8 \mathrm{~m}$ \\
\hline Reference depth of inlet & $h_{0}=1 \mathrm{~m}$ \\
\hline $\begin{array}{l}\text { Minimum depth for use of correction term of } \\
\text { current velocity }\end{array}$ & $h=1 \mathrm{~m}$ \\
\hline Mesh size & $\Delta x=\Delta y=50 \mathrm{~m}$ \\
\hline Time interval & $\Delta t=5 \mathrm{hrs}$ \\
\hline Calculation duration & $\begin{array}{l}27 \text { years between } 1978 \text { and } 2005 \text { in } \\
\text { reproduction } 10 \text { years in prediction }\end{array}$ \\
\hline Boundary conditions & $\begin{array}{l}q_{x}=0 \text { at landward and offshore boundaries } \\
d q_{y} / d y=0 \text { at side boundaries }\end{array}$ \\
\hline
\end{tabular}


assumed to be equal to the depth of closure due to waves $h_{c}$, and the upper depth of bathymetric changes $h_{R 2}$ was taken to be mean sea level. The initial seabed topography was assumed to be a uniform slope of $1 / 70$, and the equilibrium slope, the depth of closure and the berm height were assumed to be $1 / 70, h_{c}=8 \mathrm{~m}$ and $h_{R}=3 \mathrm{~m}$, respectively.

Assuming that the breaker height was $H_{b}=3 \mathrm{~m}$ and the incident angle of waves at the breaking point was $\alpha_{b}=10^{\circ}, K_{y}$ was adjusted so that the initial longshore sand transport was $2.0 \times 10^{5} \mathrm{~m}^{3} / \mathrm{yr}$, and the dynamically stable condition, under which constant longshore sand transport occurs, was reproduced by setting $K_{x}=0.2 K_{y}$.

For the boundary conditions, sand transport across the boundary was set to be 0 at the structural boundary. Although the actions of both waves and ebb tidal currents simultaneously occur in the tidal inlet, it was assumed that no sand was supplied by the ebb tidal currents. The other coefficients used in the calculation are shown in Table 1. The calculation results are presented in a new coordinate system $(X, Y)$, in which the $X$ - and $Y$-axes were taken to be the longshore and cross-shore directions (positive for offshore), respectively.

\section{RESULTS OF CALCULATION}

Figure 2(a) shows the predicted bathymetry in 1978 given the parallel contours before the extension of the jetty. Because the westward longshore sand transport was obstructed by the ebb tidal currents and the sand was deposited in the offshore zone, the initial parallel contours started to protrude offshore of the inlet. A steep slope was formed in the offshore zone deeper than $h_{c}$ owing to the deposition of sand. Figure 2(b) shows the predicted bathymetry of the ebb tidal delta in 2005 . The scale of the ebb tidal delta increased and it increasingly protruded with time, implying that longshore sand supply to the west coast was reduced by the deposited sand.

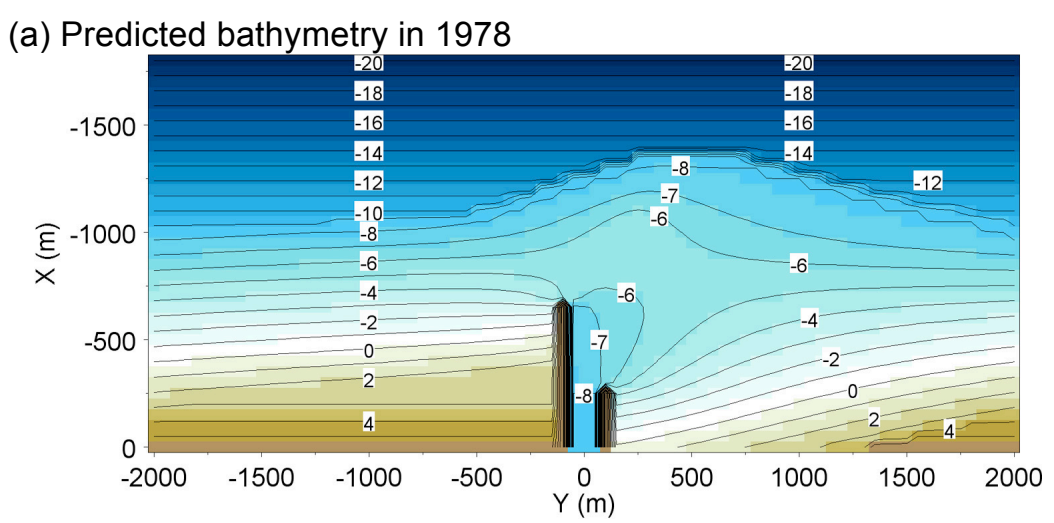

(b) Predicted bathymetry in 2005

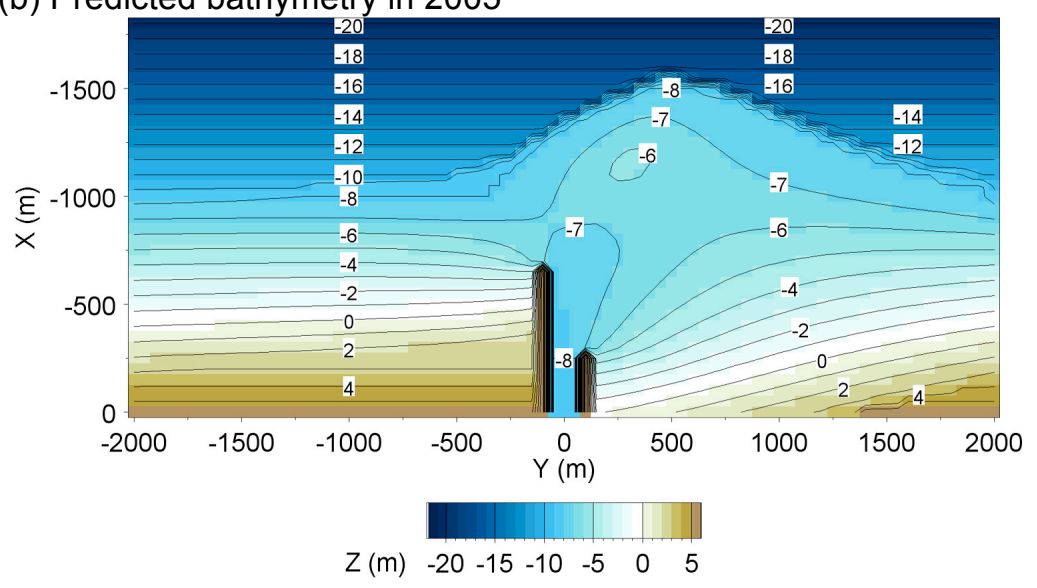

Figure 2. Predicted bathymetries around Imagire-guchi jetty in 1978 and 2005.

Figure 3 shows the bathymetry measured in 2005 and the change in the 8-m-depth contour over time. It is clear that the ebb tidal delta developed over time. Serizawa et al. (2008) predicted the bathymetry of an ebb tidal delta under a dynamically stable condition, but in this study, the prediction of its evolution, which corresponds well to the measured changes, was also demonstrated. 


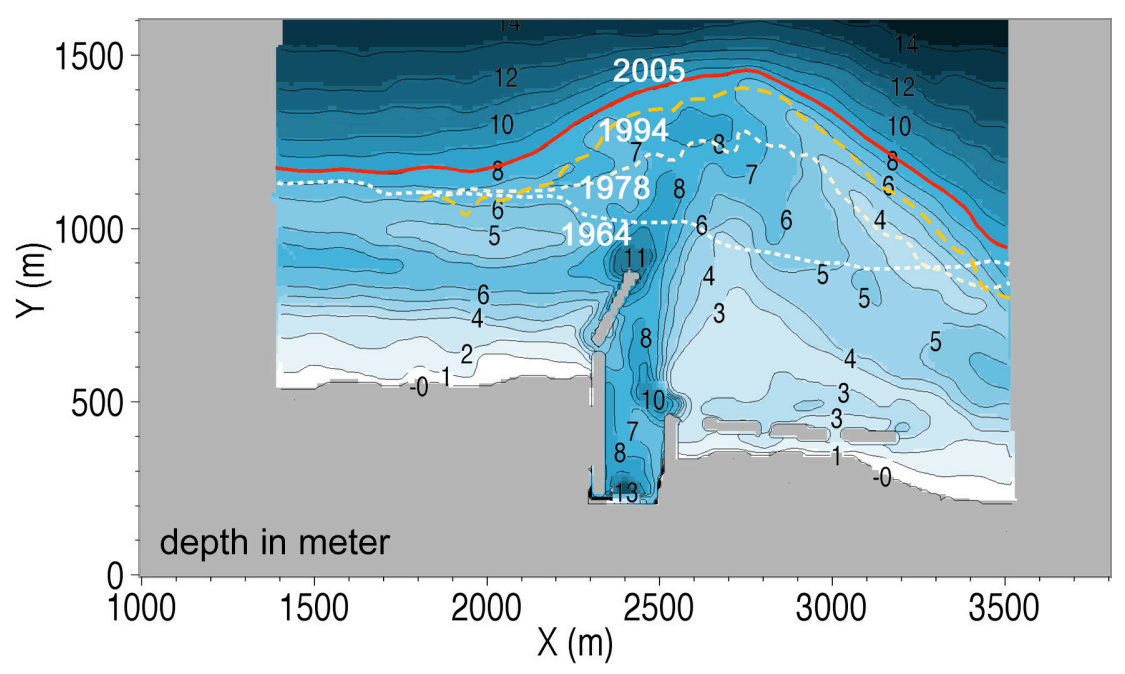

Figure 3. Measured bathymetry in 2005 and change in $8 \mathrm{~m}$ contour over time.

Figure 4(a) shows the planar distribution of the predicted bathymetric changes between 1978 and 2005. A sand deposition zone with the shape of a slender band was formed along the marginal area of the ebb tidal delta, whereas erosion occurred in an extensive area around the tip of the jetty and shoreward of the sand deposition zone. These predicted distributions are in good agreement with the actual changes between 1978 and 2005 shown in Fig. 4(b).

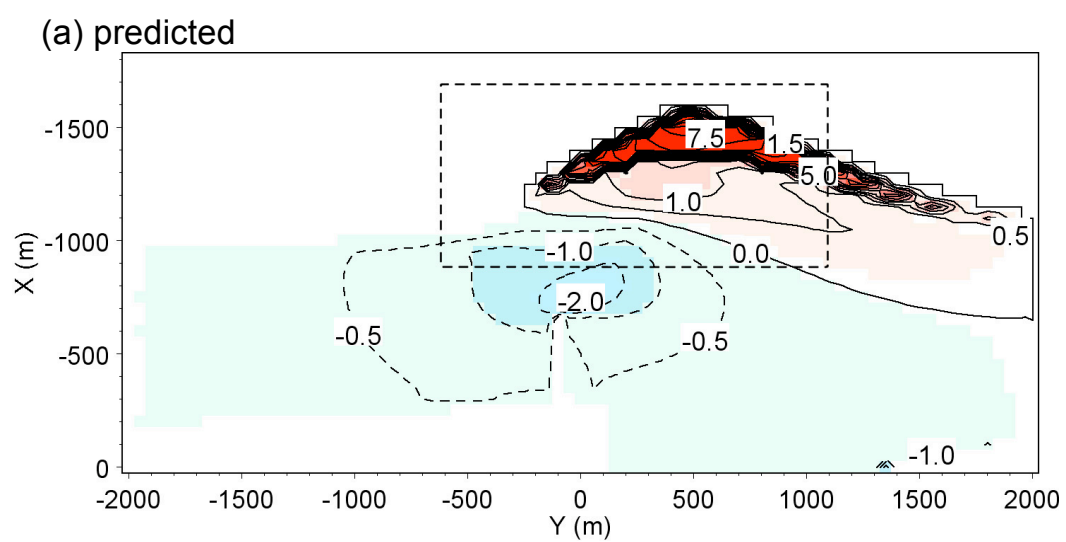

(b) measured

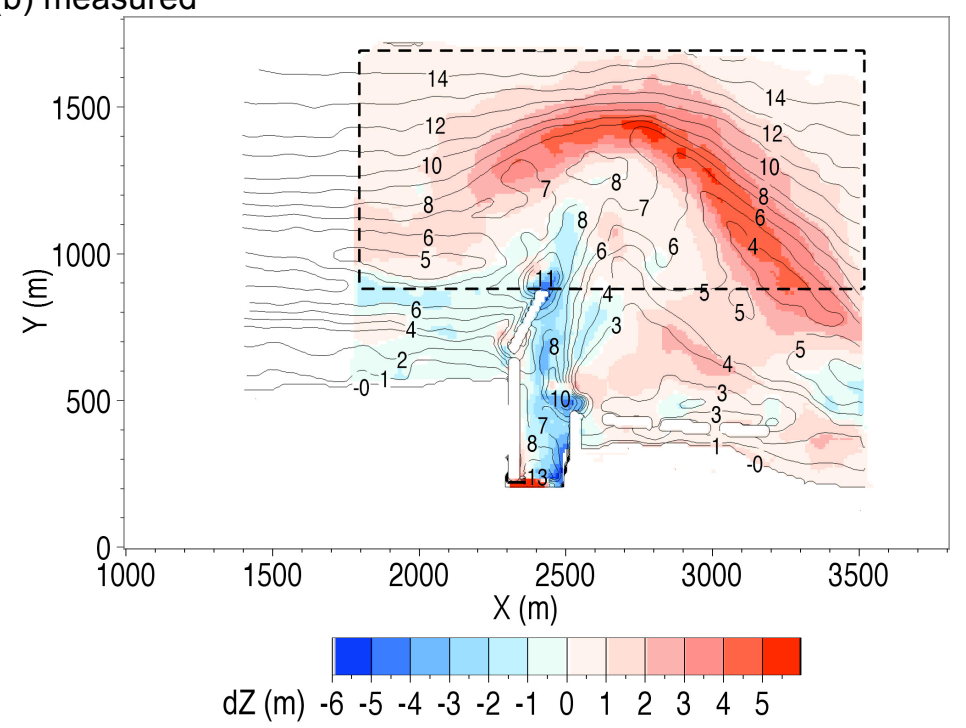

Figure 4. Measured and predicted bathymetric changes between 1978 and 2005. 
On the basis of the bathymetric survey data since 1978, we evaluated the total volume of sand forming the ebb tidal delta and the volume of this sand that was deposited in the zone deeper than $10 \mathrm{~m}$ (larger than $h_{c}$ ) and thus was difficult to transport shoreward under wave action. Figure 5 shows the change in sand volume in the rectangular zone under investigation shown by the broken line in Fig. 4. The total volume of sand in the region increased at an average rate of $9.6 \times 10^{4} \mathrm{~m}^{3} / \mathrm{yr}, 3.6 \times 10^{4} \mathrm{~m}^{3} / \mathrm{yr}$ of which was transported offshore into the zone deeper than $10 \mathrm{~m}$; i.e., almost half the sand was lost into the offshore zone. Figure 6 shows a comparison of the predicted and measured volumes of sand transported offshore into the zone deeper than $10 \mathrm{~m}$. Both results are in good agreement.

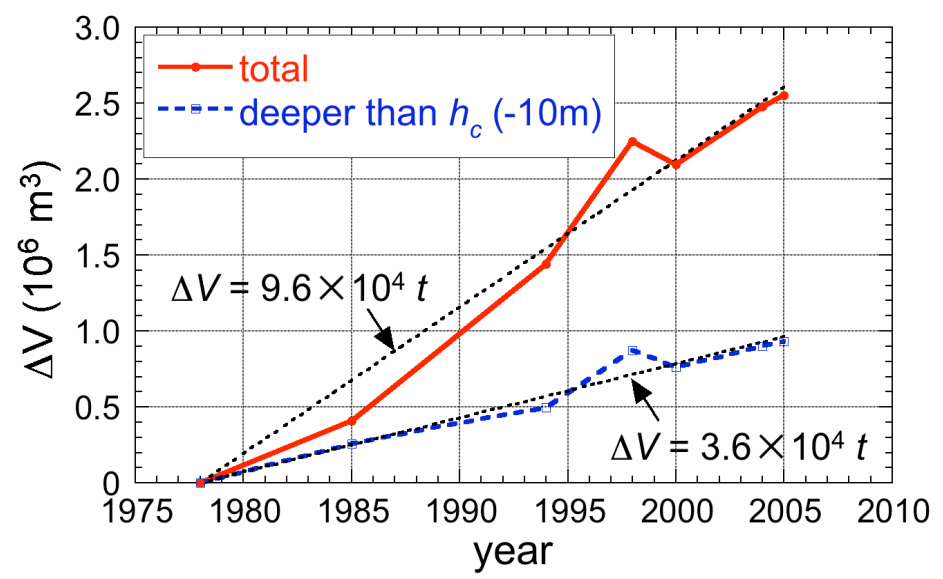

Figure 5. Change in sand volume over time in rectangular zone under investigation.

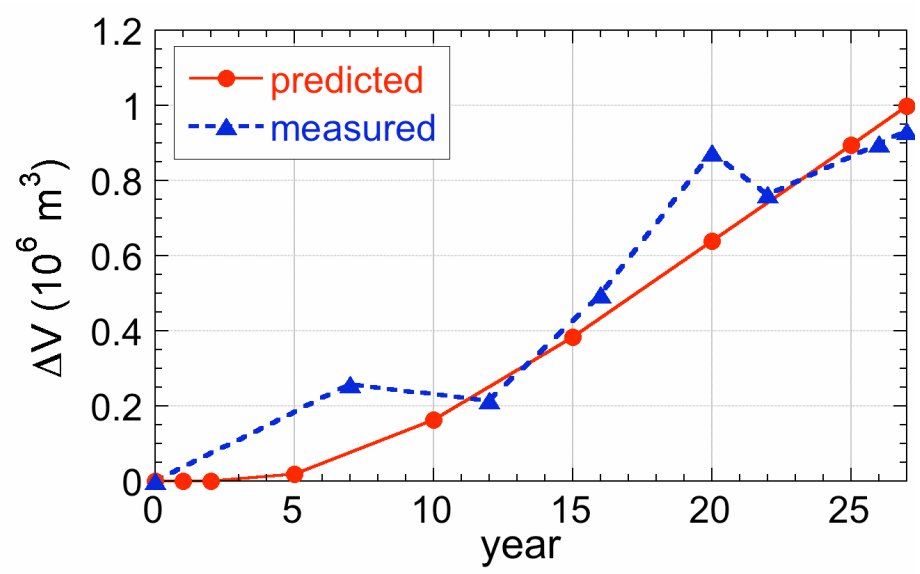

Figure 6. Predicted and measured volumes of sand transported offshore into the zone deeper than $10 \mathrm{~m}$.

\section{MEASURES AGAINST EROSION}

Since the development of the ebb tidal delta was successfully predicted, measures for preventing the loss of sand into the offshore zone were investigated. Given the numerically predicted bathymetry for 2005 as the initial topography, the results after 10 years were compared for different scenarios. As possible measures, four cases were considered. In case 1 , the present conditions are retained. In case 2 , the intensity coefficient of the ebb tidal currents $K_{v}$ is reduced from 0.3 to 0.15 . Cases 3 and 4 correspond to ordinary sand bypassing and cross-shore sand bypassing, respectively. In case 4, sand is excavated in a square zone offshore of the inlet with $250 \mathrm{~m}$ width and length, the depth of which ranges between $6 \mathrm{~m}$ and $7 \mathrm{~m}$, and dredged sand is discharged immediately downcoast of the jetty in the depth zone between the shoreline and $2 \mathrm{~m}$. In each case, the rate of transport is set to $1.0 \times 10^{5} \mathrm{~m} / 3 / \mathrm{yr}$.

Figure 7(a) shows the planar distribution of depth changes from 2005 in case 1 . Sand was deposited along the marginal area of the ebb tidal delta, causing the loss of part of the westward longshore sand transport. In case 2 , in which the intensity of ebb tidal currents was reduced to half that under the present conditions, sand was deposited in an extensive area immediately offshore of the jetty, 
as shown in Fig. 7(b). Furthermore, an erosion zone extended offshore of this sand deposition zone, and sand deposition along the marginal area of the ebb tidal delta was markedly reduced compared with that in case 1 . In practical applications, however, it is difficult to adopt this method as a measure because the tidal range and the shape of Lake Hamana are almost constant.

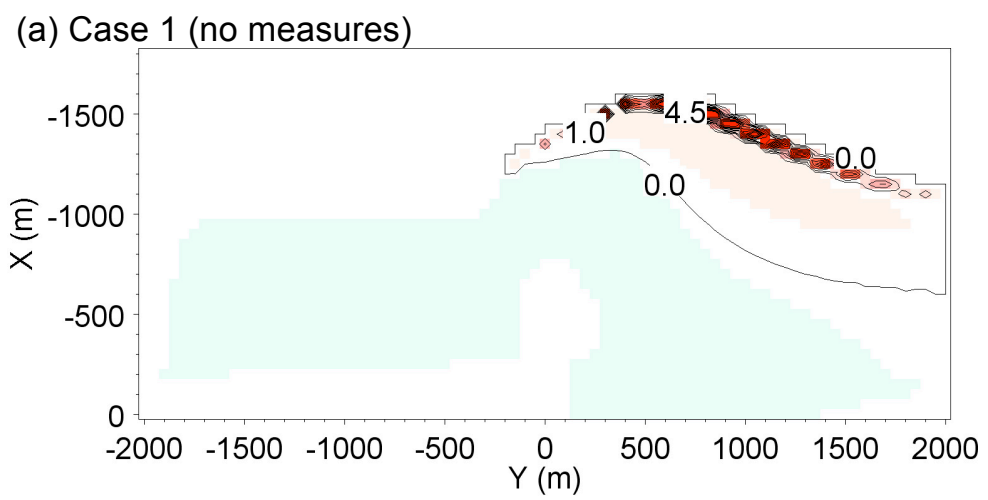

(b) Case $2\left(K_{y}\right.$ is reduced from 0.3 to 0.15$)$

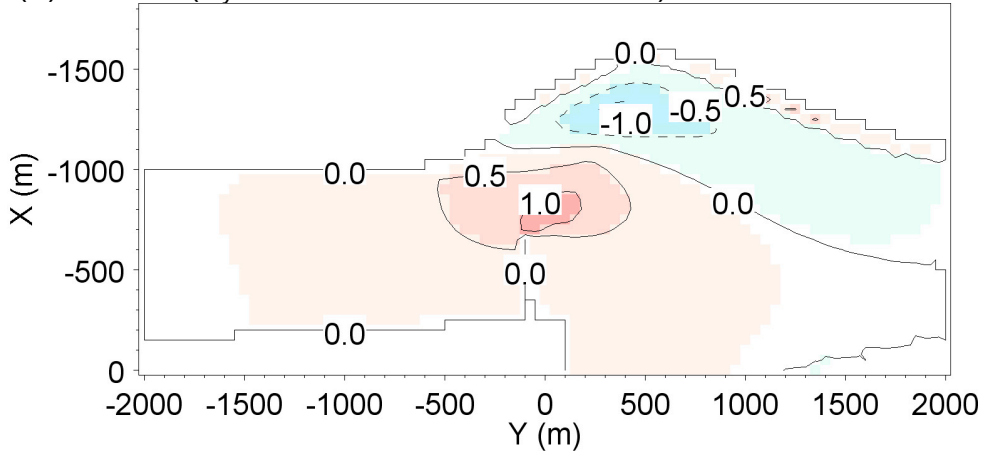

(c) Case 3 (ordinary sand bypassing)

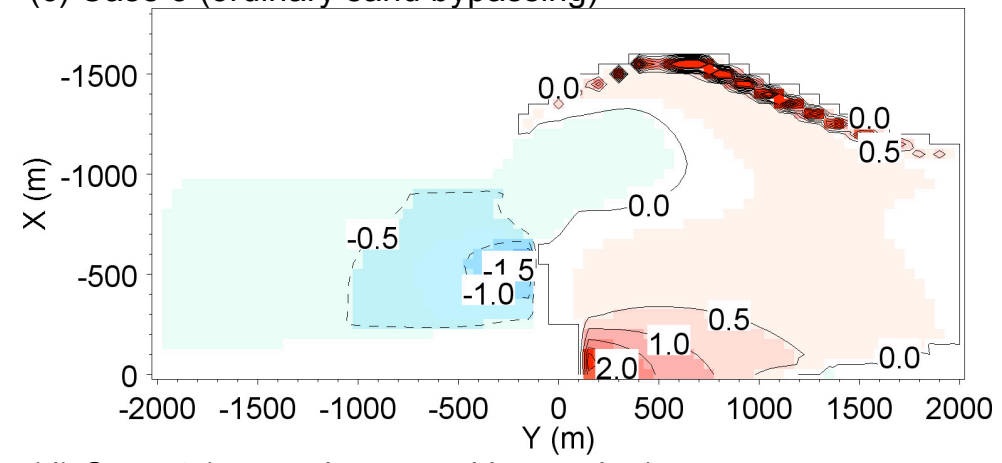

(d) Case 4 (cross-shore sand bypassing)

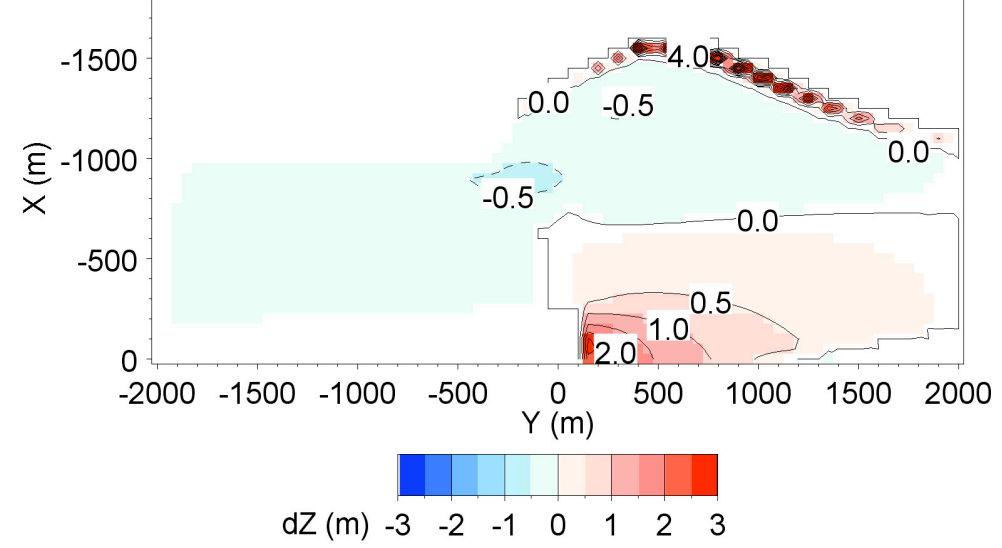

Figure 7. Planar distribution of bathymetric changes in cases 1-4. 
Figure 7(c) shows the results of ordinary sand bypassing (case 3), in which sand was taken from the vicinity of the shoreline in a depth zone ranging between 0 and $2 \mathrm{~m}$ upcoast of the jetty and the same amount of sand was supplied downcoast of the jetty. Comparing the result for case 3 with the topographic changes in case 1, the sand deposition along the marginal area of the ebb tidal delta is approximately the same, although erosion and deposition occurred upcoast and downcoast, respectively, in case 3 owing to the sand bypassing. Thus, case 3 was ineffective in terms of preventing sand loss into the offshore zone.

Figure 7(d) shows the results of cross-shore sand bypassing (case 4), in which sand is excavated in the square zone with $250 \mathrm{~m}$ width and length, the depth of which ranges between $6 \mathrm{~m}$ and $7 \mathrm{~m}$. In this case, the sand volume deposited in the marginal area of the ebb tidal delta was reduced and instead, a sand deposition zone extended downcoast of the jetty because of sand nourishment in the nearshore zone. From this viewpoint, cross-shore sand bypassing is found to be effective in preventing both offshore sand loss of part of the longshore sand transport and downcoast erosion, and it is greatly superior to ordinary sand bypassing in terms of preventing the loss of sand.

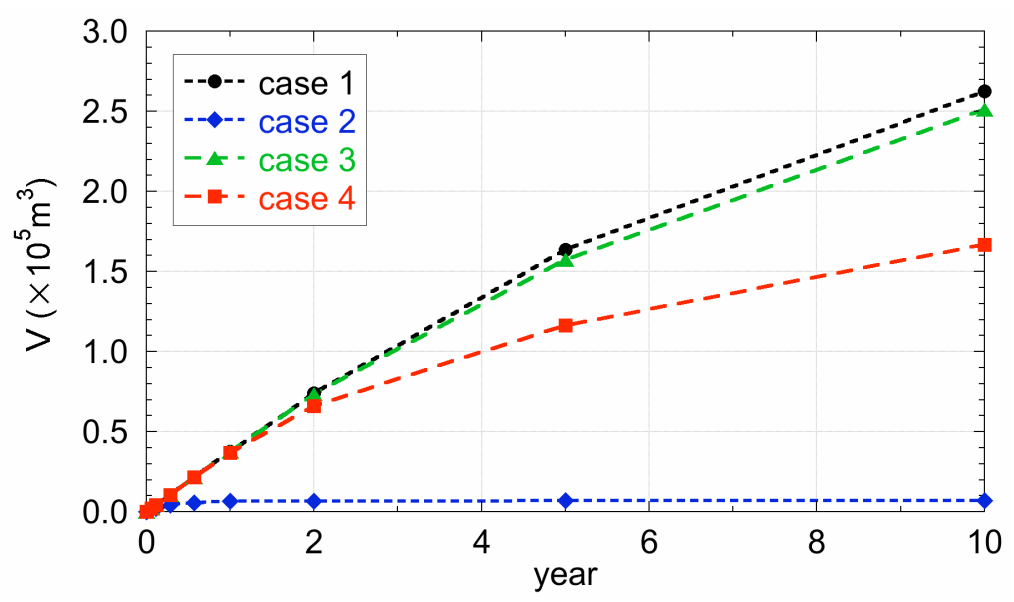

Figure 8. Sand loss into zone offshore of $10 \mathrm{~m}$ depth.

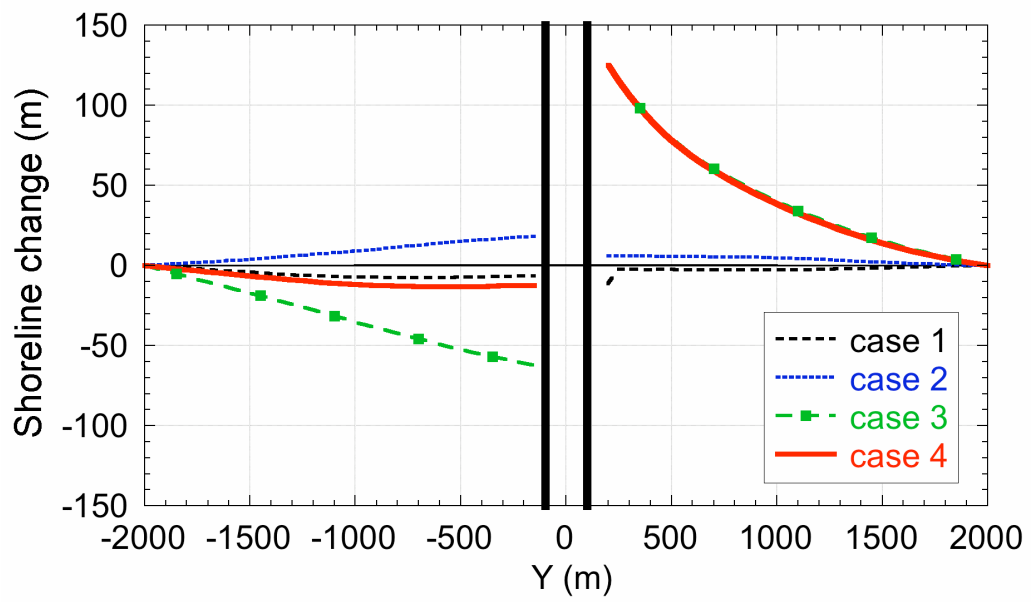

Figure 9. Shoreline changes in cases 1-4.

Figure 8 shows the change in the volume of sand lost into the zone deeper than $10 \mathrm{~m}$ over time. The most effective method is case 2 , in which the intensity of ebb tidal currents was reduced to half that under the present conditions, whereas case 1 resulted in the largest sand loss. The second most effective method is cross-shore sand bypassing (case 4). Figure 9 shows the shoreline changes in each case with reference to the shoreline in the reproduction calculation, as shown in Fig. 2. The shoreline changes in case 2 , in which the intensity of ebb tidal currents was reduced, are negligibly different from 
those in case 1 . In the ordinary sand bypassing method, both shoreline advance downcoast and shoreline recession upcoast simultaneously occur. In contrast, the most effective method for reducing downcoast erosion is cross-shore sand bypassing (case 4).

\section{CONCLUSIONS}

1. A model for predicting bathymetric changes around an ebb tidal delta was developed, and it was applied to the prediction of bathymetric changes around Imagire-guchi jetty between 1978 and 2005 as an example of bathymetric changes resulting from the extension of a jetty.

2. The predicted bathymetric changes were compared with the measured changes and they were in good agreement.

3. Some measures for preventing sand loss into the offshore zone around the tidal inlet were studied and the greater effectiveness of cross-shore sand bypassing, in which sand excavated from the offshore seabed is discharged downcoast of the jetty to reduce the loss of sand into the offshore zone, than ordinary sand bypassing was shown.

4. In the present method the fundamental equations of nearshore and tidal currents are not solved, and thus, it has a practical advantage that the computation load is much smaller than that of other methods in which these fundamental equations are directly solved.

\section{REFERENCES}

Bagnold, R. A. 1963. Mechanics of Marine Sedimentation, in The Sea, M. N.Hill (ed.), Vol. 3, 507-528, Wiley, New York.

Bailard, J. A. and D. L. Inman. 1981. An energetics bedload model for a plane sloping beach; local transport, J. Geophy. Res., Vol. 86, C3, 2035-2043.

Inman, D. L. and R. A. Bagnold. 1963. Littoral Processes, in The Sea, M. N. Hill (ed.), Vol. 3, 529-533, Wiley, New York.

Sakai, K., T. Uda, M. Serizawa, T. Kumada and Y. Kanda. 2006. Model for predicting threedimensional sea bottom topography of statically stable beach, Proc. 30th ICCE, 3184-3196.

Serizawa, M., T. Uda, T. San-nami and K. Furuike. 2006. Three-dimensional model for predicting beach changes based on Bagnold's concept, Proc. 30th ICCE, 3155-3167.

Serizawa, M., T. Uda, T. San-nami, K. Furuike and T. Ishikawa. 2008. Model for predicting formation of dynamically stable ebb tidal delta off tidal inlet, Proc. 31st ICCE, 2291-2302.

Syamsidik, S. Aoki and S. Kato. 2008. Effects of tidal currents and waves on bottom suspended sediment fluxes off two river mouths, Proc. 18th Int. Offshore (Ocean) and Polar Eng. Conf., Vancouver.

Tung, T. T., M. J. F. Stive, J. van de Graaff and D. J. R. Walstra. 2007. Morphological behavior of seasonal closure of tidal inlets, Coastal Sediments '07, 1589-1600. 